\title{
Clinical characteristics and sociodemographic features of psychotic major depression
}

Meng-qi Wang ${ }^{1+} \mathbb{0}$, Ran-ran Wang ${ }^{1}$, Yu Hao ${ }^{1}$, Wei-feng Xiong ${ }^{1}$, Ling Han ${ }^{1}$, Dong-dong Qiao ${ }^{2^{*}}$ and Juan $\mathrm{He}^{1^{*}}$

\begin{abstract}
Background: Psychotic major depression (PMD) is a subtype of depression with a poor prognosis. Previous studies have failed to find many differences between patients with PMD and those with non-psychotic major depression (NMD) or schizophrenia (SZ). We compared sociodemographic factors (including season of conception) and clinical characteristics between patients with PMD, NMD, and schizophrenia. Our aim was to provide data to help inform clinical diagnoses and future etiology research.

Methods: This study used data of all patients admitted to Shandong Mental Health Center from June 1, 2016 to December 31, 2017. We analyzed cases who had experienced an episode of PMD (International Classification of Diseases, Tenth Revision codes F32.3, F33.3), NMD (F32.0-2/9, F33.0-2/9), and SZ (F20-20.9). Data on sex, main discharge diagnosis, date of birth, ethnicity, family history of psychiatric diseases, marital status, age at first onset, education, allergy history, and presence of trigger events were collected. Odds ratios (OR) were calculated using logistic regression analyses. Missing values were filled using the k-nearest neighbor method.
\end{abstract}

Results: PMD patients were more likely to have a family history of psychiatric diseases in their first-, second-, and third-degree relatives ([OR] 1.701,95\% confidence interval [Cl] 1.019-2.804) and to have obtained a higher level of education (OR 1.451, 95\% Cl 1.168-1.808) compared with depression patients without psychotic features. Compared to PMD patients, schizophrenia patients had lower education (OR 0.604, 95\% Cl 0.492-0.741), were more often divorced (OR 3.087, 95\% Cl 1.168-10.096), had a younger age of onset (OR 0.934, 95\% Cl 0.914-0.954), less likely to have a history of allergies (OR $0.604,95 \% \mathrm{Cl} 0.492-0.741$ ), and less likely to have experienced a trigger event 1 year before first onset (OR $0.420,95 \% \mathrm{Cl} 0.267-0.661$ ). Season of conception, ethnicity, and sex did not differ significantly between PMD and NMD or schizophrenia and PMD.

Conclusions: PMD patients have more similarities with NMD patients than SZ patients in terms of demographic and clinical characteristics. The differences found between PMD and SZ, and PMD and NMD correlated with specificity of the diseases. Furthermore, allergy history should be considered in future epidemiological studies of psychotic disorders.

\footnotetext{
*Correspondence: qiaochina74@126.com; hejuan6428@sina.com ${ }^{\dagger}$ Meng-qi Wang-first author

${ }^{1}$ School of Traditional Chinese Medicine, Beijing University of Chinese Medicine, No 11, Bei San Huan East Road, Chaoyang District, Beijing 100029, China

2 Shandong Provincial Mental Health Hospital, No 49, Wenhua East Road, Jinan 250014, Shandong, China
}

\section{Background}

Psychotic major depression (PMD) is a serious mental disorder, where patients suffer from a combination of low mood and psychosis. PMD is a subtype of major depressive disorder according to the classification systems of psychiatric diseases, the DSM-V and ICD-10 [1], and accounts for about $14.7 \%-18.5 \%$ of patients with major

(c) The Author(s) 2021. This article is licensed under a Creative Commons Attribution 4.0 International License, which permits use, sharing, adaptation, distribution and reproduction in any medium or format, as long as you give appropriate credit to the original author(s) and the source, provide a link to the Creative Commons licence, and indicate if changes were made. The images or other third party material in this article are included in the article's Creative Commons licence, unless indicated otherwise in a credit line to the material. If material is not included in the article's Creative Commons licence and your intended use is not permitted by statutory regulation or exceeds the permitted use, you will need to obtain permission directly from the copyright holder. To view a copy of this licence, visit http://creativeco mmons.org/licenses/by/4.0/. The Creative Commons Public Domain Dedication waiver (http://creativecommons.org/publicdomain/ zero/1.0/) applies to the data made available in this article, unless otherwise stated in a credit line to the data. 
depression [2, 3]. However, compared with major depression without psychotic features, PMD is associated with longer duration [4], greater morbidity and mortality [5], lower response to antidepressants and psychotherapy [3, 6], higher rate of suicide risk [6], higher comorbidity of anxiety disorders [7], cognitive dysfunction [8], somatic disorders, and personality disorders $[9,10]$.

Psychotic symptoms are a risk factor for conversion from unipolar depression to bipolar disorder $[11,12]$ or schizophrenia (SZ) [13]. A longitudinal study of patients with PMD admitted to hospital for the first time showed that $41 \%$ of patients who were initially diagnosed with PMD, met DSM-IV criteria for bipolar disorder or schizoaffective disorder within 2 years [14]. Furthermore, depression is common in different stages of $\mathrm{SZ}$ and may play a role in the progression of SZ, which has raised questions around the validity of a PMD diagnosis [15, 16]. Therefore, further work on the differential etiology of PMD from other psychoses is needed [17].

In general, previous studies have failed to find many demographic differences between patients with PMD and those without psychotic features [18]. However, there have been some exceptions; family history $[19,20]$ of psychosis increased the risk for PMD, and ethnicity [4, 14] and educational attainment $[4,19,21]$ were correlated with psychotic features in depression patients.

Studies comparing PMD and SZ have found differences in sex [19, 22], age of onset [19, 22], and marital status [23]. A number of psychosocial risk factors have also been associated with a follow-up diagnosis of PMD and $\mathrm{SZ}$, which include living alone, having basic-level education, being unemployed, having less than monthly contact with friends, having no close confidants, and having experienced childhood adversity [17]. Family history of psychosis has long been recognized as an important predictor of schizophrenia [24] and major depression [25]. However, whether there is a difference in the probability of family history of mental disorder between patients with schizophrenia/non-psychotic major depression (NMD) and PMD has not been investigated. Previous studies have investigated potential associations between season of birth and major depression [26, 27, 30] as well as SZ [28]. However, in most studies, PMD was either not identified as a separate condition [26,29] or was excluded [27]. To the best of our knowledge, only a few studies have investigated the association between season of conception and psychotic features in patients with major depression.

There have been consistent reports of an association between pollen allergy symptoms and low mood among patients with seasonal mental disorder [30-32]. An epidemiological study has demonstrated that the prevalence of autoimmune disease was significantly higher in individuals with SZ and their parents compared with unaffected controls [33]. We hypothesize that a history of allergies can help identify different psychotic conditions. Thus, we also investigated allergy history in our study.

In this study, inpatients with PMD were compared with those with NMD and SZ using measures of sociodemographic factors (including season of conception) and clinical characteristics. We examined the relative importance of various clinical features of PMD to identify characteristics that are reliably associated with the diagnosis of PMD.

\section{Methods \\ Setting}

This paper was based on data from patients admitted to Shandong Mental Health Center from June 1, 2016 to December 31, 2017. Shandong Mental Health Center is the only provincial psychiatric hospital in Shandong province, with more than 900 inpatient beds. The database from which our data were acquired contained patients' number of admissions, age, sex, admission year, main discharge diagnosis, date of birth, ethnicity, family history of psychiatric diseases, marital status, age at first onset, education, allergy history, and presence of trigger events. For each patient, the main discharge diagnosis was made by a qualified psychiatrist at time of discharge from the hospital. Diagnoses were based on the ICD-10 Classification of Mental and Behavioural Disorders: Clinical Descriptions and Diagnostic Guidelines [34].

\section{Sample}

Inclusion criteria were: patients who had experienced an episode of PMD (International Classification of Diseases, Tenth Revision codes F32.3, F33.3), depression (F32.02/9, F33.0-2/9), and SZ (F20-20.9). In total, 1788 cases were identified.

Exclusion criteria were: evidence of psychotic symptoms precipitated by an organic cause or developmental retardation (10 patients with SZ, 7 with NMD, and 3 with PMD), repeated admissions of the same patient (a total of 242 multiple admissions, only the record of the first admission was included), and patients who were not born in Shandong province (to minimize the influence of provincial cultural differences, 78 patients with SZ, 27 with NMD, and 5 with PMD). The final totals of included patients were 98 patients with PMD, 351 with NMD, and 967 with SZ.

\section{Clinical characteristics}

Family history of psychiatric diseases was defined as at least one family member with a diagnosis of mental disorder within the patient's first-, second-, or third-degree relatives. Age of onset was defined as the patient's age 
at the first episode of the disorder. Trigger events were defined as stressful life events [35] (e.g., changing jobs, death in the family, failing exams, relationship problems, and other events that induced negative emotions in the patient) reported by the patient or their accompanying family members during the year prior to their first diagnosis. A positive allergy history was defined as having an allergy to food, drugs, pollen, etc.

\section{Sociodemographic factors}

Marital status was determined by the patient's relationship status at the time of treatment. For example, if a patient had been divorced but had remarried at the time of the medical record, they were classified as married. Education was divided into four categories: primary school or below, junior middle school (compulsory education, usually between the ages of 12 and 15 years) or vocational school (students who do not meet the high school entrance exam score go to vocational school to learn a professional skill), senior high school or junior college (students who do not meet the university entrance exam score go to junior college), and university or higher. The Chinese population is made up of 56 distinctive ethnic groups, with Han Chinese comprising $92 \%$ of the population. Therefore, ethnicity was classified as either Chinese Han or one of the other 55 ethnic minorities.

Date of conception was calculated based on patients' date of birth. Expected delivery date is calculated as 280 days from the first day of the last menstrual period of a pregnant woman. We assumed that fertilization occurred during ovulation (i.e., the 14th day of the last menstrual period), which would indicate that the date of birth minus 266 days would be the date of conception. The season of conception was classified according to the month of conception (spring: February-April; summer: May-August, autumn: September-October, and winter: November-January). All factors were self-reported or reported by family members who accompanied the patient.

\section{Statistical analyses}

The data were analyzed using SPSS 22.0 and R 3.6.1 for Windows (64 bit). Data are presented as number and percentages for categorical variables, and non-normal continuous variables are reported as medians (interquartile range $[\mathrm{IQR}])$. Mann-Whitney $U$ tests were used to compare age of onset between NMD and PMD and between PMD and schizophrenia. Differences in missing data between diagnostic groups were compared using Fisher's exact test. Intergroup differences were compared using a Mantel Haenszel Chi-square test or Fisher's exact test for categorical variables. Variables with $p<0.10$ were included in the logistic regression analysis. Family history of psychiatric diseases and sex were included in the model as effect-modifying variables. Odds ratios (OR) were calculated using logistic regression analyses. Missing values were filled using the K-nearest neighbor method $(k=15$ and meth $=$ median, so that the most frequent value of the 15 neighbors were filled in the missing values) [36]. The findings were considered statistically significant when the two-tailed analyses resulted in $p<0.05$. Categorical variables were transformed into serial numbers: sex $(1=$ male, $2=$ female), marital status $(1=$ unmarried, $2=$ married, $3=$ widowed, $4=$ divorced $)$, family history of psychiatric illness $(1=$ yes, $0=$ no), allergy history $(1=$ yes, $0=$ no), season of conception (1=spring, $2=$ summer, $3=$ autumn, $4=$ winter $)$, education $(1=$ primary school or below, $2=$ junior high or vocational school, $3=$ senior high school or junior college, $4=$ university and above), and ethnicity $(1=$ Han, $2=$ minority).

\section{Results \\ Distribution of sociodemographic factors and clinical characteristics}

The distribution of sociodemographic factors and clinical characteristics is presented in Table 1. Patients with PMD were significantly more educated than patients with NMD and SZ $\left(\chi^{2}=11.631, p<0.001\right.$ for NMD and $X^{2}=40.888, P<0.001$ for SZ). Patients with SZ were significantly younger at the first psychotic episode $(U=31,244.50, p<0.001)$ than those with PMD. No statistically significant differences were observed between the PMD and NMD groups' age of onset $(U=15,969.5$, $p=0.317$ ). The percentage of unmarried patients in the PMD group was significantly lower than that in the SZ group $\left(x^{2}=16.253, p<0.001\right)$, but was not significantly different to the NMD group $\left(\chi^{2}=2.118, p=0.555\right)$. Patients with SZ were significantly less likely to have a history of allergy compared with patients with PMD $\left(x^{2}=7.545, p=0.006\right)$. There was no significant difference in allergy history between the PMD and NMD groups $\left(\chi^{2}=2.463, p=0.155\right)$.

Patients with PMD were significantly more likely to have experienced trigger events within 1 year before the first episode of psychosis $\left(\chi^{2}=14.939, p<0.001\right)$ compared with the SZ group. No significant difference in trigger events were found between the PMD and NMD groups $\left(\chi^{2}=0.734, p=0.379\right)$. Compared with the NMD group, the PMD group was significantly more likely to have a family history of psychiatric diseases $\left(\chi^{2}=4.567\right.$, $p=0.033$ ), but this was not found between the PMD and SZ groups $\left(\chi^{2}=0.833, p=0.362\right)$. There were fewer patients conceived in autumn in the PMD group (16.3\%, $n=6)$ than in the NMD $(24.6 \%, n=86)$ and SZ $(21.6 \%$, 
Table 1 Distribution of social-demographic factors and clinical characteristics

\begin{tabular}{|c|c|c|c|}
\hline & $\begin{array}{l}\mathrm{NMD} \\
n(\%)\end{array}$ & $\begin{array}{l}\text { PMD } \\
n(\%)\end{array}$ & $\begin{array}{l}\mathrm{SZ} \\
n(\%)\end{array}$ \\
\hline \multicolumn{4}{|l|}{ Marital status } \\
\hline Unmarried & $93(27)$ & $33(33.7)$ & $474(49.4)^{*}$ \\
\hline Married & $222(64.5)$ & $58(59.2)$ & $368(38.4)$ \\
\hline Widowed & $13(3.8)$ & $2(2.0)$ & $17(1.8)$ \\
\hline Divorced & $16(4.7)$ & $5(5.1)$ & $100(10.4)$ \\
\hline \multicolumn{4}{|l|}{ Family history } \\
\hline Yes & $74(21.3)^{*}$ & $31(31.6)$ & $261(27.3)$ \\
\hline \multicolumn{4}{|l|}{ Sex } \\
\hline Male & $153(43.6)$ & $44(44.9)$ & $516(53.4)$ \\
\hline \multicolumn{4}{|l|}{ Allergy history } \\
\hline Yes & $37(10.5)$ & $16(16.3)$ & $78(8.1)^{*}$ \\
\hline \multicolumn{4}{|l|}{ Educational attainment } \\
\hline Primary school or below & $136(40.4)^{*}$ & $18(18.4)$ & $458(49.5)^{*}$ \\
\hline $\begin{array}{l}\text { Junior middle or vocational } \\
\text { school }\end{array}$ & $93(27.6)$ & $32(32.7)$ & $236(25.5)$ \\
\hline Senior high or junior college & $66(19.6)$ & $34(34.7)$ & $144(15.6)$ \\
\hline University and above & $42(12.5)$ & $14(14.3)$ & $88(9.5)$ \\
\hline \multicolumn{4}{|l|}{ Trigger events } \\
\hline Yes & $188(53.9)$ & $48(49.0)$ & $289(29.9)^{*}$ \\
\hline \multicolumn{4}{|l|}{ Ethnicity } \\
\hline Han & $341(98)$ & $94(97.9)$ & $932(97.8)$ \\
\hline Minority & $7(2)$ & $2(2.1)$ & $21(2.2)$ \\
\hline \multicolumn{4}{|l|}{ Season of conception } \\
\hline Spring & $84(24.0)$ & $27(27.6)$ & $241(24.9)$ \\
\hline Summer & $90(25.7)$ & $25(25.5)$ & $278(28.7)$ \\
\hline Autumn & $86(24.6)$ & $16(16.3)$ & 209 (21.6) \\
\hline Winter & $90(25.7)$ & 30 (30.6) & $239(24.1)$ \\
\hline \multicolumn{4}{|l|}{ Onset age } \\
\hline Median (IQR) & $36(22-52)$ & $34(21-49)$ & $24(19-31)^{*}$ \\
\hline
\end{tabular}

IQR interquartile range, $P M D$ psychotic major depression, NMD non-psychotic major depression, SZ schizophrenia

${ }^{*} P<0.05$ compared with PMD patients

$n=209)$ groups. However, these differences were not statistically significant. In addition, there were no significant differences between the groups for sex or ethnicity.

\section{Missing data}

Table 2 shows the comparison of missing data between the PMD, SZ, and NMD groups. There were no significant differences between the diagnostic groups in terms of missing data.

\section{PMD vs NMD}

Table 3 shows the adjusted ORs for the associations between each risk factor and diagnostic groups using the NMD group as the reference group. Having a family
Table 2 Distribution of missing data

\begin{tabular}{llllll}
\hline Diagnosis & NMD & PMD & SZ & $X^{2}$ & $P$ \\
\hline Sex & $0 / 351$ & $0 / 98$ & $0 / 967$ & & \\
Ethnicity & $3 / 351$ & $2 / 98$ & $14 / 967$ & 1.296 & 0.493 \\
Marital status & $7 / 351$ & $0 / 98$ & $8 / 967$ & 3.496 & 0.174 \\
Allergy history & $0 / 351$ & $0 / 98$ & $0 / 967$ & & \\
Trigger events & $2 / 351$ & $0 / 98$ & $1 / 967$ & 2.724 & 0.335 \\
Educational attainment & $14 / 351$ & $0 / 98$ & $41 / 967$ & 5.080 & 0.080 \\
Age at onset & $2 / 349$ & $0 / 98$ & $21 / 967$ & 5.148 & 0.058 \\
Season of conception & $0 / 351$ & $0 / 98$ & $0 / 967$ & & \\
\hline
\end{tabular}

history of psychiatric disease was significantly associated with a diagnosis of PMD $(p=0.039$, OR 1.701, 95\% confidence interval [CI] 1.019-2.804). For every additional educational level, the risk of psychotic symptoms increased by $1.451(p<0.001$, OR $1.451,95 \%$ CI 1.168 1.808 ), with the NMD group as the reference.

\section{Schizophrenia vs PMD}

Results of the logistic analysis comparing schizophrenia with PMD (reference) are presented in Table 4. Education ( $p<0.001$, OR $0.604,95 \%$ CI $0.492-0.741)$, having an allergy history ( $p=0.01$, OR $0.433,95 \%$ CI $0.233-0.842)$, presence of trigger events $(p<0.001$, OR $0.420,95 \%$ CI $0.267-0.661)$, and age at first onset $(p<0.001$, OR 0.934, 95\% CI 0.914-0.954) significantly differentiated the diagnostic groups when family history and sex were controlled in the model. Being divorced $(p=0.037)$ remained significant (OR 3.087, 95\% CI 1.168-10.196) compared schizophrenia to PMD.

\section{Discussion}

As expected, our findings indicate that PMD is more like NMD than SZ. PMD patients differed from NMD patients only in educational level and family history of psychiatric diseases. Older age of onset, presence of trigger events during the year before the first episode, not being divorced, higher level of education, and having a history of allergy helped to differentiate PMD from SZ. The results were generally in line with previous studies.

People with PMD were more likely to have a family history of a psychiatric diseases compared with people with NMD, which is consistent with a previous study [18]. To our surprise, we found no difference in family history of psychiatric diseases between the PMD and SZ groups. This highlights a potential link between heredity and psychotic symptoms.

Our findings concerning age of onset in the PMD and SZ groups are consistent with earlier studies [19, 22]. Previous studies that compared age of onset between 
Table 3 Odds ratios and 95\% Cls compared PMD with NMD, adjusted for sex and family history

\begin{tabular}{|c|c|c|c|c|c|c|c|c|c|}
\hline \multirow[t]{2}{*}{ Parameter } & \multirow[t]{2}{*}{ B } & \multirow[t]{2}{*}{ Std. error } & \multirow[t]{2}{*}{$Z$} & \multirow[t]{2}{*}{$d f$} & \multirow[t]{2}{*}{ P } & & \multirow[t]{2}{*}{ OR } & \multicolumn{2}{|c|}{$95 \% \mathrm{Cl}$ for OR } \\
\hline & & & & & & & & Lower & Upper \\
\hline Intercept & -2.189 & 0.315 & 48.233 & 1 & & $<0.001$ & 0.112 & 0.059 & 0.205 \\
\hline $\begin{array}{l}\text { Educational } \\
\text { attainment }\end{array}$ & 0.372 & 0.111 & 11.169 & 1 & & $<0.001$ & 1.451 & 1.168 & 1.808 \\
\hline \multicolumn{10}{|l|}{ Sex } \\
\hline Male & $0^{a}$ & & & & & & 1 & & \\
\hline Female & -0.110 & 0.235 & 0.218 & 1 & & 0.640 & 0.896 & 0.566 & 1.423 \\
\hline \multicolumn{10}{|c|}{ Family history } \\
\hline No & $0^{\mathrm{a}}$ & & & & & & 1 & & \\
\hline Yes & 0.531 & 0.258 & 4.252 & 1 & & 0.039 & 1.701 & 1.019 & 2.804 \\
\hline
\end{tabular}

Table 4 Odds ratios and 95\% Cls compared schizophrenia with PMD, adjusted for sex and family history

\begin{tabular}{|c|c|c|c|c|c|c|c|c|}
\hline \multirow[t]{2}{*}{ Parameter } & \multirow[t]{2}{*}{$B$} & \multirow[t]{2}{*}{ Std. error } & \multirow[t]{2}{*}{ Z } & \multirow[t]{2}{*}{$d f$} & \multirow[t]{2}{*}{$P$} & \multirow[t]{2}{*}{ OR } & \multicolumn{2}{|c|}{$95 \% \mathrm{Cl}$ for OR } \\
\hline & & & & & & & Lower & Upper \\
\hline Intercept & 5.732 & 0.435 & 173.765 & 1 & 0 & 308.497 & 135.634 & 748.346 \\
\hline $\begin{array}{l}\text { Educational } \\
\text { attainment }\end{array}$ & -0.504 & 0.104 & 23.358 & 1 & $<0.001$ & 0.604 & 0.492 & 0.741 \\
\hline \multicolumn{9}{|c|}{ Allergy history } \\
\hline No & $0^{\mathrm{a}}$ & & & & & 1 & & \\
\hline Yes & -0.838 & 0.326 & 6.605 & 1 & 0.010 & 0.433 & 0.233 & 0.842 \\
\hline \multicolumn{9}{|l|}{ Trigger events } \\
\hline No & $0^{a}$ & & & & & 1 & & \\
\hline Yes & -0.867 & 0.231 & 14.130 & 1 & $<0.001$ & 0.420 & 0.267 & 0.661 \\
\hline \multicolumn{9}{|l|}{ Marital status } \\
\hline Unmarried & $0^{\mathrm{a}}$ & & & & & 1 & & \\
\hline Married & 0.231 & 0.305 & 0.575 & 1 & 0.448 & 1.260 & 0.695 & 2.303 \\
\hline Widowed & 0.980 & 0.874 & 1.257 & 1 & 0.262 & 2.665 & 0.567 & 19.959 \\
\hline Divorced & 1.127 & 0.541 & 4.339 & 1 & 0.037 & 3.087 & 1.168 & 10.096 \\
\hline \multicolumn{9}{|c|}{ Family history } \\
\hline No & $0^{\mathrm{a}}$ & & & & & 1 & & \\
\hline Yes & -0.378 & 0.249 & 2.313 & 1 & 0.128 & 0.685 & 0.424 & 1.126 \\
\hline $\begin{array}{l}\text { Age at first } \\
\text { onset }\end{array}$ & -0.068 & -0.011 & 39.791 & 1 & $<0.001$ & 0.934 & 0.914 & 0.954 \\
\hline \multicolumn{9}{|l|}{ Sex } \\
\hline Male & $0^{\mathrm{a}}$ & & & & & 1 & & \\
\hline Female & 0.071 & 0.244 & 0.087 & 1 & 0.768 & 1.074 & 0.667 & 1.736 \\
\hline
\end{tabular}

PMD and NMD patients were inconsistent. In some studies, patients with PMD had a younger age of onset [22], whereas in others, there was no significant difference [37]. In our study, the age at first episode did not differ between PMD and NMD.

A previous study compared PMD and schizophrenia patients with a population-based sample of controls without a history of psychosis and showed that PMD and $\mathrm{SZ}$ patients experienced a major life event in the year before onset more often than controls, though the difference did not reach statistical significance ( $p=0.058$ for PMD and $p=0.056$ for SZ) [17]. In the present study, more patients with PMD reported stressful life events within the year before onset compared with schizophrenia patients, which suggests a difference in the pathological mechanisms between the two disorders. However, it is important to note that patients with SZ may be more likely to underreport trigger 
events because of their difficulties in cooperating with doctors [38].

To our knowledge, this is the first study that included allergy history in the analysis. Surprisingly, we found a significant difference between patients with SZ with PMD. Our findings revealed that PMD patients were more likely to have had an allergy compared with SZ patients. Several lines of evidence have identified a link between non-celiac gluten sensitivity and symptoms of neuropsychiatric disorders $[39,40]$. In our study, we included history of all types of allergies (e.g., drug, food, and pollen allergies). Although this result requires further verification, it does offer some insight for pathological studies focused on PMD.

For sociodemographic factors, season of conception was not different between any of the groups. We also found that the higher the level of education, the more likely the patients experienced psychotic symptoms, which is inconsistent with previous studies that reported no difference or a reverse relationship in patients with NMD and PMD [4, 19, 41]. These inconsistencies may be attributed to these studies defining education based on possession of a college degree or not $[4,41]$, whereas our study divided education into four levels.

We found no significant sex differences between the diagnostic groups. Differences in sample size may contribute to the discrepant findings between our and previous studies [19, 22].

As expected, having been divorced had a strong effect for identifying SZ from PMD in the current study, which is in accordance with a previous study [23].

Differences between Chinese ethnic minority and Han populations have received little attention in previous epidemiological studies that compared PMD patients with NMD and SZ patients. Our finding that ethnicity did not differ between groups was not surprising because there were very few patients who belonged to the ethnic minority group.

\section{Limitations}

There are some limitations in this study. For example, because of the small sample size, the effects of some factors (such as ethnicity and marital status) could not be fully tested. Furthermore, patient data were retrieved from medical records, which sometimes lack information, and thus may lead to some bias. Additionally, presence of trigger events was determined based on patients' self-report and not using a validated tool. Structured clinical interview using DSM criteria, or research diagnostic criteria would have significantly strengthened the validity of this study.

\section{Conclusions}

Our results suggest that patients with PMD are similar to NMD patients in terms of demographic and clinical characteristics. PMD patients were more likely to have a family history of psychiatric illness in their first-, second-, or third-degree relatives and a higher level of education. We found that there were more differences between patients with PMD and those with SZ. These differences may be due to differing pathological mechanisms underlying each condition.

Season of conception did not differentiate PMD from NMD or SZ, while allergy history should be considered in future epidemiological studies of psychotic disorders. The relationship between family history and psychotic features needs further exploration. Further work on the differential etiology of PMD from other psychoses is needed.

\section{Abbreviations}

PMD: Psychotic major depression; NMD: Non-psychotic major depression; SZ: Schizophrenia; OR: Odds ratios; $\mathrm{Cl}$ : Confidence interval.

\section{Supplementary Information}

The online version contains supplementary material available at https://doi. org/10.1186/s12991-021-00341-7.

Additional file 1. Data

\section{Acknowledgements}

The authors thank Dr. Audrey Holmes and Dr. Sarina Iwabuchi from Liwen Bianji, Edanz Editing China (https://www.liwenbianji.cn/ac) for editing the English text of a draft of this manuscript. The authors also thank the editors and reviewers for their suggestions and efforts.

\section{Authors' contributions}

MW: methodology, formal analysis, writing-original draft, visualization. RW: investigation, writing - review and editing. YH: writing —review and editing. WX: investigation. LH: methodology, review and editing. JH: conceptualization, supervision, funding acquisition, project administration, validation. DQ: supervision, resources, data curation, validation. All authors have read and approved the manuscript.

\section{Funding}

This study was supported by the National Natural Science Foundation of China (ID number 81574098). The funders had no role in the study design, data collection and analysis, decision to publish, or preparation of the manuscript. All authors state that this research was conducted independently of the influence of funding bodies.

\section{Availability of data and materials}

Research data have been uploaded with the paper in Additional file 1 "data. xIsx" and can be requested from doramaia@sina.com.

\section{Declarations}

\section{Ethics approval and consent to participate}

This study was conducted in accordance with the tenets of the Declaration of Helsinki and was approved by the ethical committee of the National Natural

Science Foundation of China. The research did not directly involve any human 
body. Patient data were extracted from monthly reports maintained by Shandong Mental Health Center. All individual-level data were anonymous.

\section{Consent for publication}

This manuscript is approved by all authors for publication.

\section{Competing interests}

The authors have declared that no competing interests exist.

Received: 27 May 2020 Accepted: 7 March 2021

Published online: 26 March 2021

\section{References}

1. Rothschild AJ. Challenges in the treatment of major depressive disorder with psychotic features. Schizophr Bull. 2013;39(4):787-96. https://doi. org/10.1093/schbul/sbt046.

2. Johnson J, Jim M. The validity of major depression with psychotic features based on a community study. Arch Gen Psychiatr. 1991;48(12):1075. https://doi.org/10.1001/archpsyc.1991.01810360039006.

3. Ohayon MM, Schatzberg AF. Prevalence of depressive episodes with psychotic features in the general population. Am J Psychiatry. 2002:159(11):1855-61. https://doi.org/10.1176/appi.ajp.159.11.1855.

4. Gaudiano BA, Dalrymple KL, Zimmerman M. Prevalence and clinical characteristics of psychotic versus nonpsychotic major depression in a general psychiatric outpatient clinic. Depress Anxiety. 2009;26(1):54-64. https://doi.org/10.1002/da.20470.

5. Thakur M, Hays J, Kishnan K. Clinical, demographic and social characteristics of psychotic depression. Psychiatry Res. 1999;86:99-106. https://doi. org/10.1016/s0165-1781(99)00030-x.

6. Dold M, Bartova L, Kautzky A, Porcelli S, Montgomery S, Zohar J, Mendlewicz J, Souery D, Serretti A, Kasper S. Psychotic features in patients with major depressive disorder: a report from the European group for the study of resistant depression. J Clin Psychiatry. 2019. https://doi.org/10. 4088/JCP.17m12090.

7. Charney DS, Nelson JC. Delusional and nondelusional unipolar depression: further evidence for distinct subtypes. Am J Psychiatry. 1981;138:328-33. https://doi.org/10.1176/ps.37.11.1157.

8. Gaudiano BA, Miller IW. Dysfunctional cognitions in hospitalized patients with psychotic versus nonpsychotic major depression. Compr Psychiatry. 2007:48:357-65. https://doi.org/10.1016/j.comppsych.2007.03.003.

9. Serretti A, Lattuada E, Cusin C, Gasperini M, Smeraldi E. Clinical and demographic features of psychotic and nonpsychotic depression. Compr Psychiatry. 1999;40:358-62. https://doi.org/10.1016/s0010-440x(99) 90141-4.

10. Tonna M, Panfilis CD, Provini C, Marchesi C. The effect of severity and personality on the psychotic presentation of major depression. Psychiatry Res. 2011. https://doi.org/10.1016/j.psychres.2011.05.005.

11. Kessing LV, Willer I, Andersen PK, Bukh JD. Rate and predictors of conversion from unipolar to bipolar disorder: a systematic review and metaanalysis. Bipolar Disord. 2017;19(5):324-35. https://doi.org/10.1111/bdi. 12513.

12. Ratheesh A, Davey C, Hetrick S, Alvarez-Jimenez M, Voutier C, Bechdolf A, et al. A systematic review and meta-analysis of prospective transition from major depression to bipolar disorder. Acta Psychiatr Scand. 2017:135(4):273-84. https://doi.org/10.1111/acps.12686.

13. Staff MC. Diagnostic shifts during the decade following first admission for psychosis. Am J Psychiatry. 2011;168(11):1186-94. https://doi.org/10. 1176/appi.ajp.2011.11010048.

14. Tohen M, Khalsa H-MK, Salvatore P, Vieta E, Ravichandran C, Baldessarini RJ. Two-year outcomes in first-episode psychotic depression. J Affect Disord. 2012;136(1-2):1-8. https://doi.org/10.1016/j.jad.2011.08.028.

15. Upthegrove R, Marwaha S, Birchwood M. Depression and schizophrenia: cause, consequence, or trans-diagnostic issue? Schizophr Bull. 2017:43:240-4. https://doi.org/10.1093/schbul/sbw097.

16. Ruggero CJ, Kotov R, Carlson GA, Tanenberg-Karant M, Gonzalez DA, Bromet EJ. Diagnostic consistency of major depression with psychosis across 10 years. J Clin Psychiatry. 2011;72:1207-13. https://doi.org/10.4088/JCP. $10 \mathrm{~m} 06774$.
17. Heslin M, Desai R, Lappin JM, Donoghue K, Morgan C. Biological and psychosocial risk factors for psychotic major depression. Soc Psychiatry. 2015;51(2):233-45. https://doi.org/10.1007/s00127-015-1131-1.

18. Ostergaard SD, Waltoft BL, Mortensen PB, Mors O. Environmental and familial risk factors for psychotic and non-psychotic severe depression. J Affect Disord. 2013;147(1-3):232-40. https://doi.org/10.1016/j.jad.2012. 11.009.

19. Jääskeläinen $E$, Juola T, Korpela H, Lehtiniemi H, Nietola M, Korkeila J, Miettunen J. Epidemiology of psychotic depression — systematic review and meta-analysis. Psychol Med. 2018;48(6):905-18. https://doi.org/10. 1017/S0033291717002501.

20. Nietola M, Huovinen $\mathrm{H}$, Heiskala A, et al. Early childhood and adolescent risk factors for psychotic depression in a general population birth cohort sample. Soc Psychiatry Psychiatr Epidemiol. 2020. https://doi.org/10. 1007/s00127-020-01835-7.

21. Park SC, Choi J, Kim JM, Jun TY, Lee MS, Kim JB, Yim HW, Park YC. Is the psychotic depression assessment scale a useful diagnostic tool? The CRESCEND study. J Affect Disord. 2014;166:79-85. https://doi.org/10.1016/j. jad.2014.05.004

22. Miika N, Anni H, Tanja N, Jouko M, Jyrki K, Erika J. Clinical characteristics and outcomes of psychotic depression in the northern Finland birth cohort 1966. Eur Psychiatr. 2018;53:23-30. https://doi.org/10.1016/j. eurpsy.2018.05.003.

23. Heslin M, Lappin JM, Donoghue K, Lomas B, Reininghaus U, Onyejiaka A, Croudace T, Jones PB, Murray RM, Fearon P, Doody GA, Dazzan P, Craig TJ, Morgan C. Ten-year outcomes in first episode psychotic major depression patients compared with schizophrenia and bipolar patients. Schizophr Res. 2016;176:417-22. https://doi.org/10.1016/j.schres.2016.04.049.

24. Tsuang M. Schizophrenia: genes and environment. Biol Psychiatry. 2000;47(3):210-20. https://doi.org/10.1016/s0006-3223(99)00289-9.

25. Monroe SM, Slavich GM, Gotlib IH. Life stress and family history for depression: the moderating role of past depressive episodes. J Psychiatr Res. 2014;49:90-5. https://doi.org/10.1016/j.jpsychires.2013.11.005.

26. Schnittker J. Season of birth and depression in adulthood: Revisiting historical forerunner evidence for in-utero effects. SSM Popul Health. 2018:4:307-16. https://doi.org/10.1016/j.ssmph.2018.03.008.

27. Seon-Cheol P, JeongKyu S, Hoon KB, JaeMin K, Tae-Youn J, Min-Soo L, et al. Potential relationship between season of birth and clinical characteristics in major depressive disorder in Koreans: results from the CRESCEND study. Yonsei Med J. 2016;57(3):784-9. https://doi.org/10.3349/ymj. 2016.57.3.784.

28. Mortensen PB, et al. Effects of family history and place and season of birth on the risk of schizophrenia. N Engl J Med. 1999. https://doi.org/10. 1056/NEJM19990225340080.

29. Talarowska M, Bliniewska K, Wargacka K, Gaecki P. Birth month and course of recurrent depressive disorders in a polish population. Med Sci Mon Int Med J Exp Clin Res. 2018;24:4169-74.

30. Manalai P, Hamilton RG, Langenberg P, Kosisky SE, Lapidus M, Sleemi A, Scrandis D, Cabassa JA, Rogers CA, Regenold WT, Dickerson F, Vittone BJ, Guzman A, Balis T, Tonelli LH, Postolache TT. Pollen-specific immunoglobulin E positivity is associated with worsening of depression scores in bipolar disorder patients during high pollen season. Bipolar Disord. 2012;14(1):90-8. https://doi.org/10.1111/j.1399-5618.2012.00983.x].

31. Postolache TT, Lapidus M, Sander ER, Langenberg P, Hamilton RG, Soriano JJ, Furst N, McDonald JS, Bai J, Scrandis DA, Cabassa JA, Stiller JW, Balis T, Guzman A, Togias A, Tonelli LH. Changes in allergy symptoms and depression scores are positively correlated in patients with recurrent mood disorders exposed to seasonal peaks in aeroallergens. Sci World J. 2007. https://doi.org/10.1100/tsw.2007.286.

32. Akram F, Jennings TB, Stiller JW, Lowry CA, Postolache TT. Mood worsening on days with high pollen counts is associated with a summer pattern of seasonality. Pteridines. 2019;30(1):133-41. https://doi.org/10.1515/pteri dines-2019-0016.

33. Eaton WW, Byrne M, Ewald H, Mors O, Chen CY, Agerbo E, Mortensen PB. Association of schizophrenia and autoimmune diseases: linkage of Danish national registers. Am J Psychiatry. 2006;163(3):521-8.

34. World Health Organization. 1992 The ICD-10 Classification of mental and behavioral disorders. Clinical descriptions and diagnostic guidelines. Geneva World Health Organization.

35. Robert FJ, Brown GW. Types of stressful life event and the onset of anxiety and depressive disorders. Psychol Med. 1981;11(4):803-15. 
36. Hastie TJ, Tibshirani R. Discriminant adaptive nearest neighbor classification. IEEE Trans Pattern Anal Mach Intell. 1996. https://doi.org/10.1109/34. 506411.

37. Buoli M, Caldiroli A, Altamura AC. Psychotic versus non-psychotic major depressive disorder: a comparative naturalistic study. Asian J psychiatr. 2013;6(4):333-7. https://doi.org/10.1016/j.ajp.2013.02.003

38. Chen N, Zou YZ, Tan SP, et al. Effect of insufficient effort on cognitive assessments in patients with schizophrenia. China Ment Health J. 2013:027(011):850-7.

39. Genuis SJ, Lobo RA. Gluten sensitivity presenting as a neuropsychiatric disorder. Gastroenterol Res Pract. 2014. https://doi.org/10.1155/2014/ 293206.
40. Lionetti E, Leonardi S, Franzonello C, Mancardi M, Ruggieri M, Catassi C. Gluten Psychosis: confirmation of a new clinical entity. Nutrients. 2015;7(7):5532-9. https://doi.org/10.3390/nu7075235.

41. Gaudiano BA, Zimmerman M. The relationship between childhood trauma history and the psychotic subtype of major depression. Acta Psychiatr Scand. 2009;121(6):462-70. https://doi.org/10.1111/j.1600-0447. 2009.01477.x.

\section{Publisher's Note}

Springer Nature remains neutral with regard to jurisdictional claims in published maps and institutional affiliations.
Ready to submit your research? Choose BMC and benefit from

- fast, convenient online submission

- thorough peer review by experienced researchers in your field

- rapid publication on acceptance

- support for research data, including large and complex data types

- gold Open Access which fosters wider collaboration and increased citations

- maximum visibility for your research: over 100M website views per year

At BMC, research is always in progress.

Learn more biomedcentral.com/submissions 